\title{
A Proposal Mathematical Model for the Vaccine COVID-19 Distribution Network: A Case Study in Mexico
}

\author{
Isidro Soria-Arguello $\mathbb{D}^{1},{ }^{1}$ Rafael Torres-Escobar ${ }^{(D)}{ }^{2}$ Hugo Alexer Pérez-Vicente ${ }^{1}{ }^{1}$ \\ and Tomas Guillermo Perea-Rivera ${ }^{1}$ \\ ${ }^{1}$ Universidad Iberoamericana Ciudad de México, Departamento de Ingeniería Química, Industrial y de Alimentos, \\ Ciudad de Mexico 01219, Mexico \\ ${ }^{2}$ Universidad Anáhuac México, Facultad de Ingeniería, Huixquilucan 52786, Mexico
}

Correspondence should be addressed to Rafael Torres-Escobar; rafael.torrese@anahuac.mx

Received 13 July 2021; Accepted 23 October 2021; Published 13 November 2021

Academic Editor: J Santos Reyes

Copyright (c) 2021 Isidro Soria-Arguello et al. This is an open access article distributed under the Creative Commons Attribution License, which permits unrestricted use, distribution, and reproduction in any medium, provided the original work is properly cited.

\begin{abstract}
Coronavirus disease 2019 (COVID-19) has been the most recent disease, with millions of deaths worldwide. Fortunately, vaccines have been developed to immunize the population. However, the distribution of the vaccine is also a significant challenge. Generally, each country defines its strategy to bring it closer to the target population, considering the adequate transport for their conservation, depending on the type of vaccines defined. In this work, a mathematical model is proposed for the distribution of different COVID-19 vaccines in Mexico. Our results suggest an efficient strategy to meet demand in a given period.
\end{abstract}

\section{Introduction}

1.1. The COVID-19 in the World. At the end of 2019, the world met one of the most lethal viruses easily spread among human beings. According to the World Health Organization (WHO), COVID-19 is an illness caused by a new coronavirus named SARS-CoV-2. The WHO heard about this new virus on December 31,2019, following a report of a cluster of cases of viral pneumonia in Wuhan, People's Republic of China. The most common symptoms are fever, dry cough, fatigue, loss of taste or smell, nasal congestion, conjunctivitis (red eyes), sore throat, headache, muscle or joint pain, nausea or vomiting, diarrhea, dizziness, among others [1].

From the first case detected in Wuhan, China, COVID19 began to spread very rapidly, especially in the Pacific area; by the end of January 2020, 14,500 cases had already been registered in the West Pacific, 39 cases in South-East Asia, 25 cases in Europe, 61 cases in America, and 9 cases in the Eastern Mediterranean. Thus, at the end of the first quarter of 2020, the cases were already in the thousands on all continents: 660 thousand accumulated cases in Europe, 321 thousand cases in America, 70 thousand cases in the Eastern
Mediterranean, 111 thousand cases in the West Pacific, 8 thousand cases in South-East Asia, and 6 thousand cases in Africa. Worldwide, the year 2021 began with 89.5 million accumulated cases, and currently, the WHO reports 168.5 million cases; Figure 1 shows a graph with current cases around the world [2].

Three massive outbreaks have been detected worldwide, called waves by the $\mathrm{WHO}$, and have forced the population to stay sheltered in their homes (see Table 1). Similarly, currently, the WHO has registered a total of 3.5 million deaths worldwide [3].

1.2. The COVID-19 in Mexico. The first contagion of COVID-19 in Mexico occurred on February 28, 2020, when a resident of Mexico City was detected as positive after returning from Italy; on the same day, a second case was confirmed in the state of Sinaloa. The previous was made known by the President of Mexico in his morning conference and the Undersecretary of Health. On March 14, 2020, the government determined the suspension of school presidential activities for one month, beginning on March 


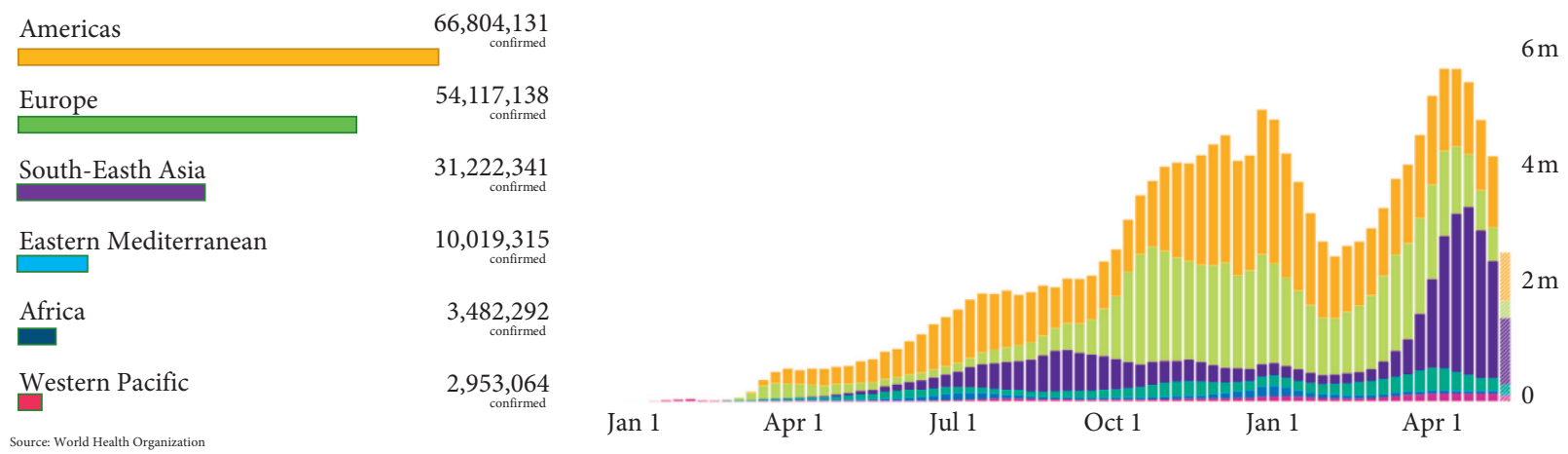

FIgURE 1: WHO coronavirus dashboard.

TABLE 1: Number of cases by region in each global coronavirus wave.

\begin{tabular}{lcc}
\hline World wave & Region & Maximum cases in one day \\
\hline & Americas & $1,000,000$ \\
200,000 & 400,000 \\
First wave at the end of July 2020 & Europe & 85,000 \\
& South-East Asia & 100,000 \\
& Eastern Mediterranean & 35,000 \\
& Africa & $2,500,000$ \\
& Western Pacific & $1,900,000$ \\
& Americas & 200,000 \\
Second wave at the beginning of 2021 & Europe & 172,000 \\
& South-East Asia & 170,000 \\
& Eastern Mediterranean & 71,000 \\
& Africa & $1,400,000$ \\
Third wave at the middle of April 2021 & Western Pacific & $1,400,000$ \\
& Americas & $2,200,000$ \\
& Europe & 378,000 \\
& South-East Asia & 49,000 \\
& Eastern Mediterranean & 131,000 \\
\end{tabular}

20th [4]. Likewise, the Undersecretary of Health announced a series of measures to prevent the spread of the coronavirus, called the National Day of Healthy Distance, which included the suspension of nonessential activities such as massive sporting events and concerts [5]. Finally, on March 18th, the first death case was presented in the country, specifically in Mexico City [6].

Regarding the number of COVID-19 infections, Mexico presented the same statistical behavior of peaks (waves) as the rest of the countries. For example, at the beginning of August 2020, the Ministry of Health reported that 9,556 new infections were registered (first wave). By December 12th, up to 12,057 new cases were recorded (second wave). Finally, on January 23, 2021, a new record number was registered for a single day: 20,057 new cases. Thus, Mexico reports 2 million 595 thousand cases (which represents $1.53 \%$ concerning the cases confirmed by the WHO) and a total of 223 thousand deaths [7].
1.3. Vaccine COVID-19 in the World. The WHO has stated that vaccines will not stop the COVID-19 pandemic but that the vaccination process is the key to prevention. In this sense, the WHO also mentions that the real challenge to stop the pandemic is to have a fair and equitable distribution of vaccines in all countries to protect their population, especially the most vulnerable people. The availability of approved vaccines does not guarantee the control of the spread of the virus, much less its eradication. The WHO confirms the use of preventive measures such as hand washing, face masks, and avoiding physical contact, even in those who have already been vaccinated [8].

Before a vaccine sees the light for its commercialization, it must pass a series of phases with its respective tests. Currently, 184 types of candidate vaccines are reported in the preclinical phase and 102 types of vaccines in the clinical phase. These vaccines are grouped either by type of platform (based on protein, RNA, DNA, inactive virus, etc.), by the 
number of doses to be delivered, or by route of administration (oral or injectable) [9].

A few months after the appearance of the first cases, countries such as the United States (USA) and the United Kingdom (UK), through commercial agreements, were the first to acquire vaccines from Oxford-AstraZeneca (May 2020). Subsequently, by the end of summer 2020, those same countries plus Canada had already purchased a greater number of doses than they actually needed to cover their respective populations. As expected, countries with higher economic incomes were the first to acquire the first vaccines. It was not until January 2021 that developing countries were able to acquire their first dose, in that case, the African Union of Nations. Table 2 shows us the list of the ten countries with the highest purchase of vaccines [10].

To date, there are countries in Latin America, Africa, and Asia that have not yet negotiated the acquisition of vaccines for their populations; the portal called Launch and Scale has calculated that a total of 11.3 billion doses have been arranged worldwide with the possibility of increasing that amount with 5.9 billion additional doses, which are found in negotiation for many countries. The global vaccination dose capacity is estimated at a total of 17.2 billion.

In response to the search for an equitable distribution of vaccines in the world, the COVAX initiative (The COVID19 Vaccines Global Access Facility) [11] arises as a result of the collaboration of various organizations such as CEPI (Coalition for Epidemic Preparedness Innovations) [12], GAVI (Global Alliance for Vaccines and Immunizations) [13], UNICEF (United Nations International Children's Emergency Fund) [14], and WHO. The objective of the COVAX initiative is to guarantee that at least $20 \%$ of the population of the countries that are affiliated have their respective doses as soon as they are available in the market, being a communication channel between vaccine manufacturers and countries with less economic capacity.

1.4. Acquisition of Vaccines COVID-19 in Mexico. We have mentioned that the first countries to establish trade agreements with pharmaceutical companies were the USA and the UK in May 2020. Although in Mexico, according to the portal of the Americas Society and the Council of the Americas, it took more than three months to carry out the first steps for the acquisition of vaccines, it was until August 12 , 2020, that Argentina announced an agreement with Mexico for the shipment of the active substance of AstraZeneca vaccine, which would be packaged by Liomont Laboratories. During the same day, the Ministry of Foreign Relations announced that, in conjunction with the Mexican entrepreneur sector, the production of the AstraZeneca vaccine would be financed to be distributed in Latin America.

In September 2020, the Russian Direct Investment Fund announced that it would supply Mexico with 32 million doses of the Sputnik V vaccine through the Landsteiner Laboratories [15]. In addition, the Mexican Government announced the signing of various agreements for the acquisition of 198 million doses of vaccines through the
WHO's COVAX initiative of AstraZeneca of Pfizer and CanSino Biologics laboratories. Mexico announced that at the same time it was negotiating to carry out phase 3 tests of the following vaccines: CanSino (China), CureVac (Germany), Janssen (USA), Novavax (USA), Sanofi-Pasteur (France), Sputnik V (Russia), and ReiThera (Italy) [16].

At the beginning of December 2020 in Mexico, the Federal Commission for the Protection against Sanitary Risks (COFEPRIS for its acronym in Spanish) approved the emergency use of the Pfizer Biontech vaccine. For this reason, on December 23, Mexico received its first shipment, and the Ministry of Finance affirmed that Mexico would allocate a total of 1.659 million dollars to cover the payment of all vaccines [17].

In January 2021, the President of Mexico announced the acquisition of 24 million doses of the Sputnik V vaccine. In this same sense, Mexico approved in February 2020 the use of the CanSino and Sinovac vaccines. In March, a commercial agreement was announced for the Chinese Sinopharm vaccine to obtain 12 million doses that began to arrive in the last week of May through the COVAX initiative [18].

1.5. Vaccine COVID-19 Distribution Network in Mexico. On January 12, 2021, the President of Mexico announced the national vaccination plan against COVID-19. The vaccination strategy was established by objectives: as the first stage, health workers in COVID-19 hospitals represent the first line of combat against this virus. The second group to be vaccinated would be that of adults over 60 years old, representing a total of 15 million. Subsequently, it will be the group of education workers to facilitate the return of students to face-to-face classes and, finally, the general population itself that will be divided into decades, starting with the population between 50 and 59 years old and so on [19].

The period between December 23, 2020, and January 12, 2021 (where about 87,000 doses of the Pfizer vaccine were applied to medical personnel), was used as a trial period to calibrate the logistics services that make up this strategy of vaccination: the arrival timing at the airport (with different shipments of vaccines) to the units where they are unpacked and shipped to various refrigeration centers was given; they had the support of the National Institute of Cancerology (INCAN for its acronym in Spanish), which has the deepfreezing infrastructure needed for the cold storage of vaccines and the National Institutes of Health in Mexico. This plan is known as the National Vaccination Strategy, in which 10,000 brigades were integrated, made up of 10 government servers and two volunteers; it is estimated that a total of 120 thousand people participated in implementing this plan and fulfilling it on time.

The Mexican army will be in charge of the national distribution of vaccines; it includes reception of the cargo upon arrival at the airport, import custom procedures, review by COFEPRIS personnel, shipment to the INCAN for unpacking, care of the cold chain, and finally, the subdivision. Subsequently, the vaccines are sent to a redistribution point where the type of transport is defined according to their destination (see Figure 2) [19]. For this, the Mexican 
TABLE 2: Total confirmed doses by entity.

\begin{tabular}{lcc}
\hline Entity & Vaccine & Grand total \\
\hline European Union & Pfizer, AstraZeneca, Moderna, Novavax, Janssen, Sanofi, CureVac, and Valneva & $2,885,000,000$ \\
COVAX & Pfizer, AstraZeneca, Moderna, Novavax, Janssen, and Sanofi & $2,361,000,000$ \\
USA & Pfizer, AstraZeneca, Moderna, Novavax, Janssen, Sanof, and Covaxin & $1,210,000,000$ \\
UK & Pfizer, AstraZeneca, Moderna, Novavax, Janssen, Sanofi, CureVac, and Valneva & $517,000,000$ \\
Brazil & Pfizer, AstraZeneca, Moderna, Janssen, Sinovac, Sputnik V, and Covaxin & $450,000,000$ \\
India & AstraZeneca, Novavax, Sputnik V, and Covaxin & $390,000,000$ \\
Canada & Pfizer, AstraZeneca, Moderna, Novavax, Janssen, Sanofi, and Medicago & $381,000,000$ \\
Japan & Pfizer, AstraZeneca, and Moderna & $314,000,000$ \\
African Union & Pfizer, Janssen, and Sputnik V \\
Indonesia & Pfizer, AstraZeneca, Novavax, Sinovac, Sinopharm, and CanSino & $270,000,000$ \\
Turkey & Pfizer, Sinovac, and Sputnik V & $255,500,000$ \\
Mexico & & $214,500,000$ \\
& Pfizer, AstraZeneca, Moderna, Novavax, Janssen, Sinovac, Sputnik V, CureVac, Sinopharm, and & $204,830,000$
\end{tabular}

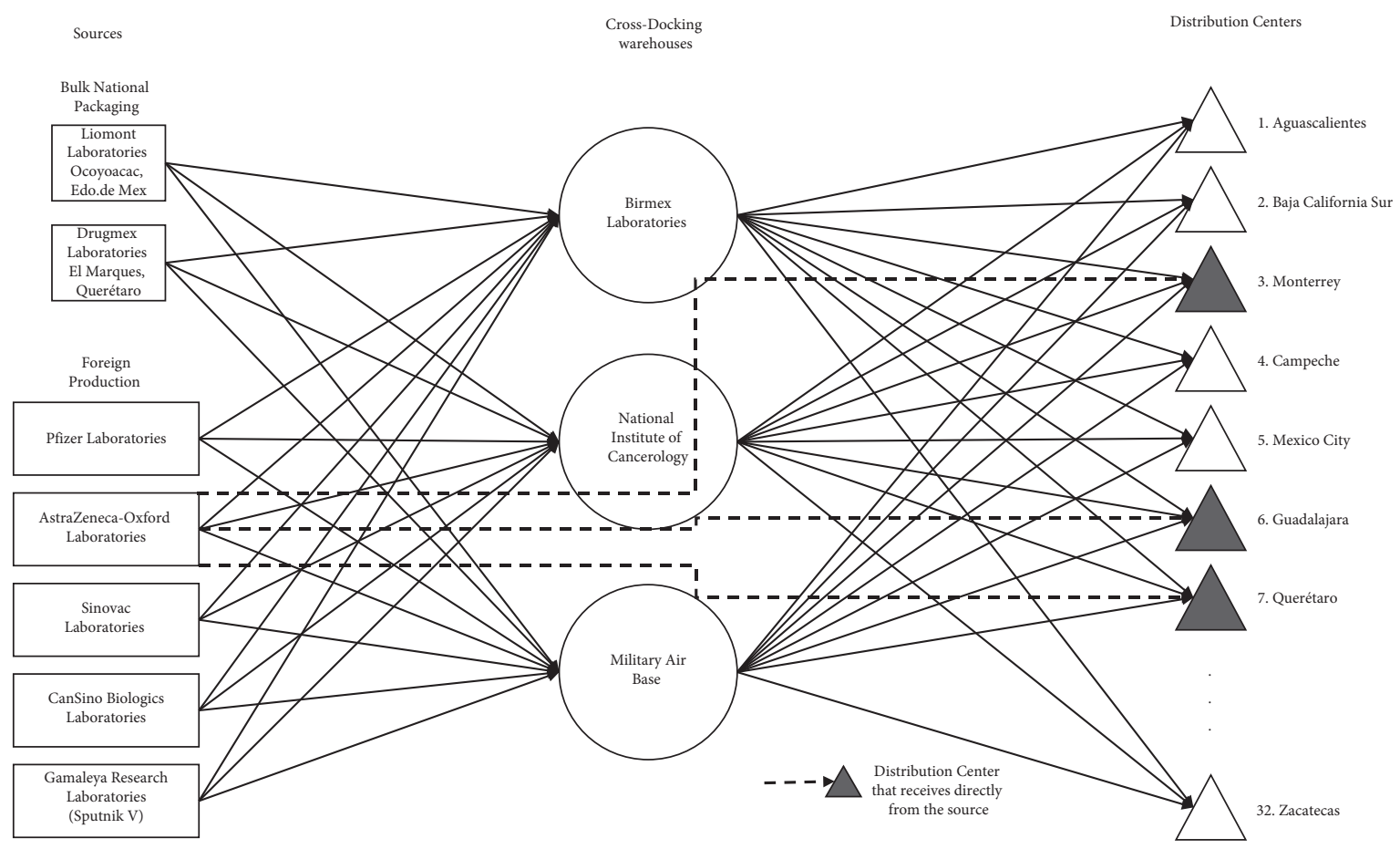

Figure 2: Vaccine distribution network in Mexico.

army has established eight airline routes and seven land routes to 32 Distribution Centers (DCs) (see Table 3) [19].

The reception of vaccines in Mexico began in December 2020, with the Pfizer Biontech brand, receiving weekly shipments mainly at the international airports of Mexico City, Monterrey, Guadalajara, and Queretaro (see Figure 3) [20].

The AstraZeneca Oxford, Sputnik V, and Sinovac vaccines began to be received in the middle of February 2021, unlike the CanSino Biologics vaccine that arrived at the end of March. Currently, all vaccines received in Mexico are presented in Table 4 [20].

\section{Related Works}

Several works have been developed to design the network for vaccine distribution from different frameworks, as summarized in [21]. In particular, the research methodology dimension is straightforward to target in applying mathematical models and solution methods.

Recently, in the research of [22], they propose a mixedinteger programming (MILP) model that includes the location of a set of DC and determination of the route flows from a central point according to the WHO recommendation. A combined method consisting of the MILP model and a metaheuristic for four sub-Saharan African countries was used to minimize annual costs. Metaheuristics use an evolutionary strategy.

A linear programming model was developed in [23] for the vaccine distribution problem in Nigeria, considering that transport is carried out every month in a finite time horizon; in addition, only one type of vehicle is used. In this model, it is assumed that there is sufficient 
TABle 3: Vaccine distribution routes in Mexico.

\begin{tabular}{lcc}
\hline Route no. & Type & Destination \\
\hline 1 & Aerial & Hermosillo-Tijuana-La Paz \\
2 & Aerial & Chihuahua-Torreon-Apodaca \\
3 & Aerial & Merida-Cancun-Chetumal-Campeche \\
4 & Aerial & Leon-San Luis Potosi-Zacatecas-Durango-Culiacan-Tepic \\
5 & Aerial & Morelia-Colima-Zapopan-Aguascalientes \\
6 & Aerial & Veracruz-Oaxaca-Tuxtla Gutierrez-Villahermosa \\
7 & Aerial & Chilpancingo-Acapulco-Zihuatanejo \\
8 & Aerial & Tampico-Ciudad Victoria-Reynosa-Nuevo Laredo \\
9 & Land & Ciudad de Mexico \\
10 & Land & Estado de Mexico \\
11 & Land & Queretaro \\
12 & Land & Puebla \\
13 & Land & Hidalgo \\
14 & Land & Tlaxcala \\
15 & Land & Morelos \\
\hline
\end{tabular}

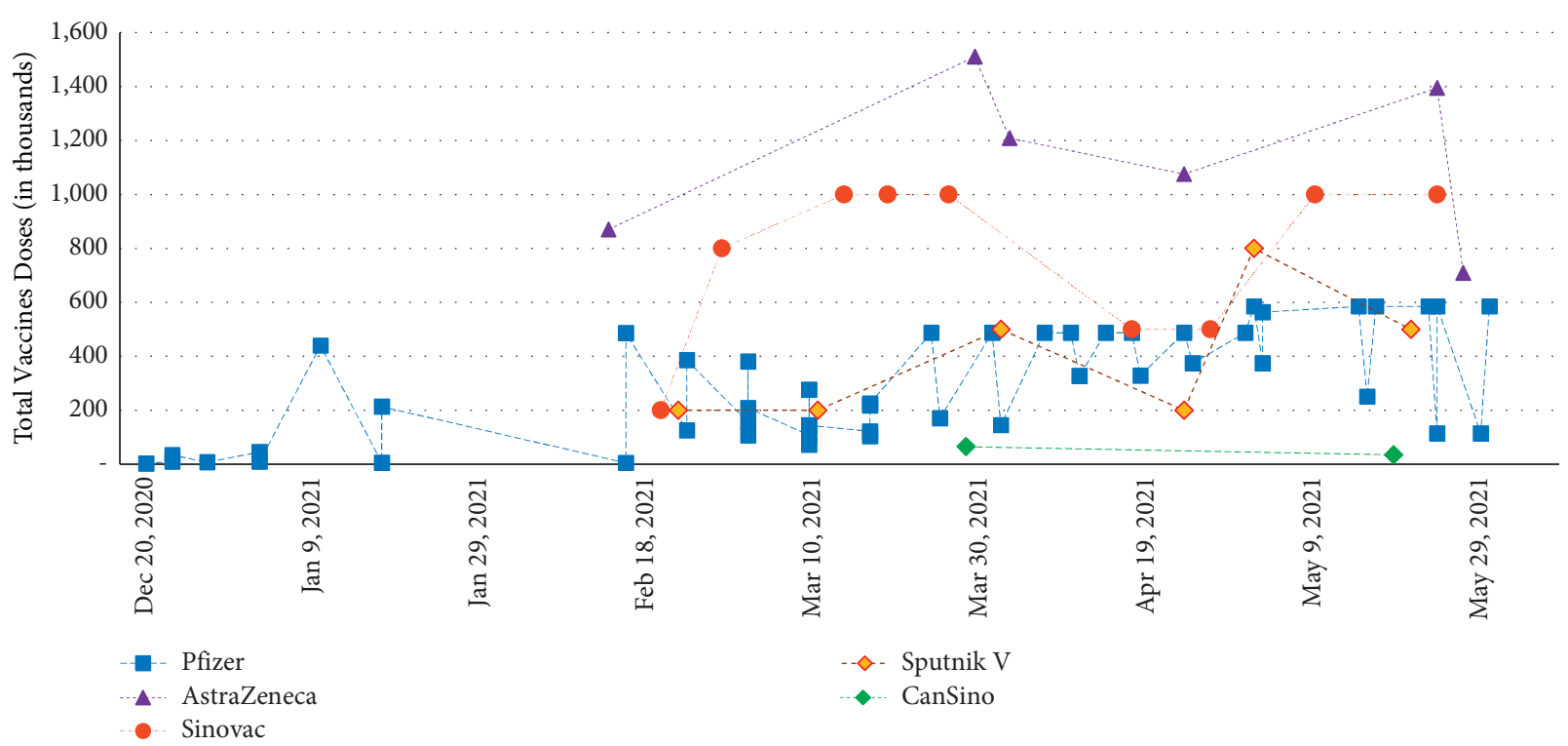

Figure 3: Arrivals of vaccines COVID-19 to Mexico 2020-2021.

TAble 4: Total vaccines received in Mexico.

\begin{tabular}{|c|c|c|}
\hline No. & Vaccine & Quantity \\
\hline 1 & Pfizer & $13,479,765$ \\
\hline 2 & Sinovac & $7,000,000$ \\
\hline 3 & AstraZeneca & $6,768,600$ \\
\hline 4 & CanSino & $4,645,301$ \\
\hline 5 & Sputnik V & $2,400,000$ \\
\hline \multicolumn{2}{|r|}{ Total } & $34,293,666$ \\
\hline
\end{tabular}

refrigeration capacity for the vaccines, and the transshipment nodes have space for vaccines; therefore, balance restrictions are included. The model serves only the population of children under two years old and pregnant women. Furthermore, it allows extending the mathematical model to expand the storage capacity. In [24], a MILP model is proposed for long- and mid-term decisions, and they make robust analyses for demands with high and low priority.
In [25], a mixed-integer programming mathematical model is proposed to minimize cholera cases in Bangladesh. They use demographic information to define different strategies considering different age groups. The model is used to administer single-dose vaccines. One of its conclusions mentions that the location of vaccines using the strategy of age or risk groups and the specific incidence rate is the most efficient to save lives and from the point of view of cost-effectiveness, as well as details on the characteristics of the vaccine (one dose vs. two) for proper planning. A study by [26] on influenza vaccine planning concludes that the targeted vaccination strategy is more effective than mass and random vaccination strategies, especially when demand is high and vaccine supply is limited.

In [27], they propose a mathematical model for designing a WHO-EPI (Expanded Program on Immunization) network to minimize the costs of vaccine distribution in any country that is considered low and middle income. Starting from a distribution network that uses a four-tier 
architecture, they design an optimal network with more flexible operational policies that combine the district and regional centers within the same pool and refer to them as hubs. Therefore, our overall problem is to design a network that moves vaccines from the central store to individual clinics across the country through a system of intermediating the centers while minimizing the total cost of transportation, facilities, and storage over the network.

In [28], he mentions the challenges faced by low- and middle-income countries for introducing new vaccines in their populations in a timely manner and the volume of such vaccines. This regard presents the benefits of redesigning Benin's vaccine supply chain using a discrete simulation model in HERMES software. This model represents the operational cold chain of the vaccine based on data from the simulated over a one-year time interval field. They conclude that it is possible to save both capital expenditures and recurring operating costs by eliminating redundancies in equipment, personnel, locations, and routes. Furthermore, his work demonstrates the value of multiple concomitant synergistic changes.

An interesting review is made in their research by [21] to assess whether the literature on supply chain design models can address critical questions for vaccine supply chain design. As a reference, they consider the existing literature on the rotavirus vaccine and establish it in five dimensions: characteristics of the network, uncertainty, performance measures, methodology, and applicability of research. One of the conclusions is that it is necessary to go beyond the existing SCND literature to model all the typical complexities of a vaccine supply chain: some decisions are determined mainly by qualitative factors or require discussions with relevant stakeholders. In a broader context of the implications of a global pandemic in CS, see [29].

In [30], they mention that having more levels in the drug supply chain reduces the ability of planners at high levels in the system to make decisions. So, they mention the importance of proposing a distribution model known as crossdocking that has the advantage of having minimal or no inventory keeping that reduces transportation costs, inventory maintenance costs, and reduction of stockouts. They propose a Large-Scale Randomized Experiment in Zambia to identify a scalable structure for distributing medicines in the health sector supply chain.

\section{Proposal Mathematical Model}

Models for vaccines distribution are sorted into seven classification criteria: decision level, methodology, part of the VDC modeled, uncertainties and characteristics, performance measures, real-life applicability, and countries and vaccines covered. The model discussed in this paper belongs to the real application and methodology models according to [31] since it considers the context of distributing vaccines against COVID-19 exclusively for Mexico. This model is the first attempt to propose an approach for the distribution of vaccines against COVID-19 in Mexico, which represents a challenge since it is one of the health emergencies of the $21^{\text {st }}$ century that requires rapid responses to achieve herd immunity in the shortest time to reactivate sectors of the local economy that the COVID-19 pandemic has hit.

3.1. Problem Definition. The COVID-19 vaccine distribution problem is studied. The current distribution network does not have a defined pattern, and the strategy used shows political biases that benefit some states and leave others vaccine-free. In general, COVID-19 vaccines that come from international sources typically enter a country via airline and are initially stored in a central warehouse usually located in the country's capital or another major city. Then, they are transported via intermediate cross-dock to states or DC. In most countries, the legacy medical supply chains typically have a four-tier arborescent structure for vaccine distribution. Although there might be one less or one more tier and the tiers might have different names, this type of structure with the hierarchical flows as shown is universal, regardless of the specific characteristics of the country in question [22]. Figure 4 shows a typical distribution network in the Mexican context.

In Table 4 , we can see that the largest number of vaccines available in Mexico as of June 2021 is from Pfizer with $39.30 \%$, followed by Sinovac with $20.40 \%$ and AstraZeneca with $19.73 \%$. The least number of vaccines that has been received is CanSino and Sputnik V with $13.54 \%$ and 6.99\%, respectively. Vaccines require storage and transport in a temperature-controlled environment. Therefore, the vaccination strategy has areas of opportunity and represents an interesting and difficult problem. The proposed methodology contributes to improving the performance of the distribution network: optimizing the operating costs associated with specialized vaccine transport and for decision-makers to use the proposed methodology to improve performance by establishing quantitative criteria for vaccine distribution.

3.2. Mathematical Formulation. The proposed mathematical model is based on the formulation developed to provide a problem of distributing mass consumer products presented in $[32,33]$; the methodology was later developed to attend other problematic as resilient supply chain model as we can see in [34]. The mathematical model is flexible and can be adapted to different problems with excellent results. In the present research work, an important simplification based on the elimination of binary variables and the addition of continuous variables of the mathematical model is presented to solve the distribution of vaccines efficiently considering a distribution according to the demands of the states.

Let $K$ be the set sources of Mexican Government approved packaging laboratories or vaccines arrived from international sources labeled as auxiliary sources. An element $k \in K$ identifies a specific source. Let $I$ be the set of the potential cross-docking warehouses. An element $i \in I$ is a specific cross-docking warehouse. Finally, let $J$ be the set of distribution centers; a particular distribution center is any $j \epsilon$ J. DCs belong to each of the states as they are usually 


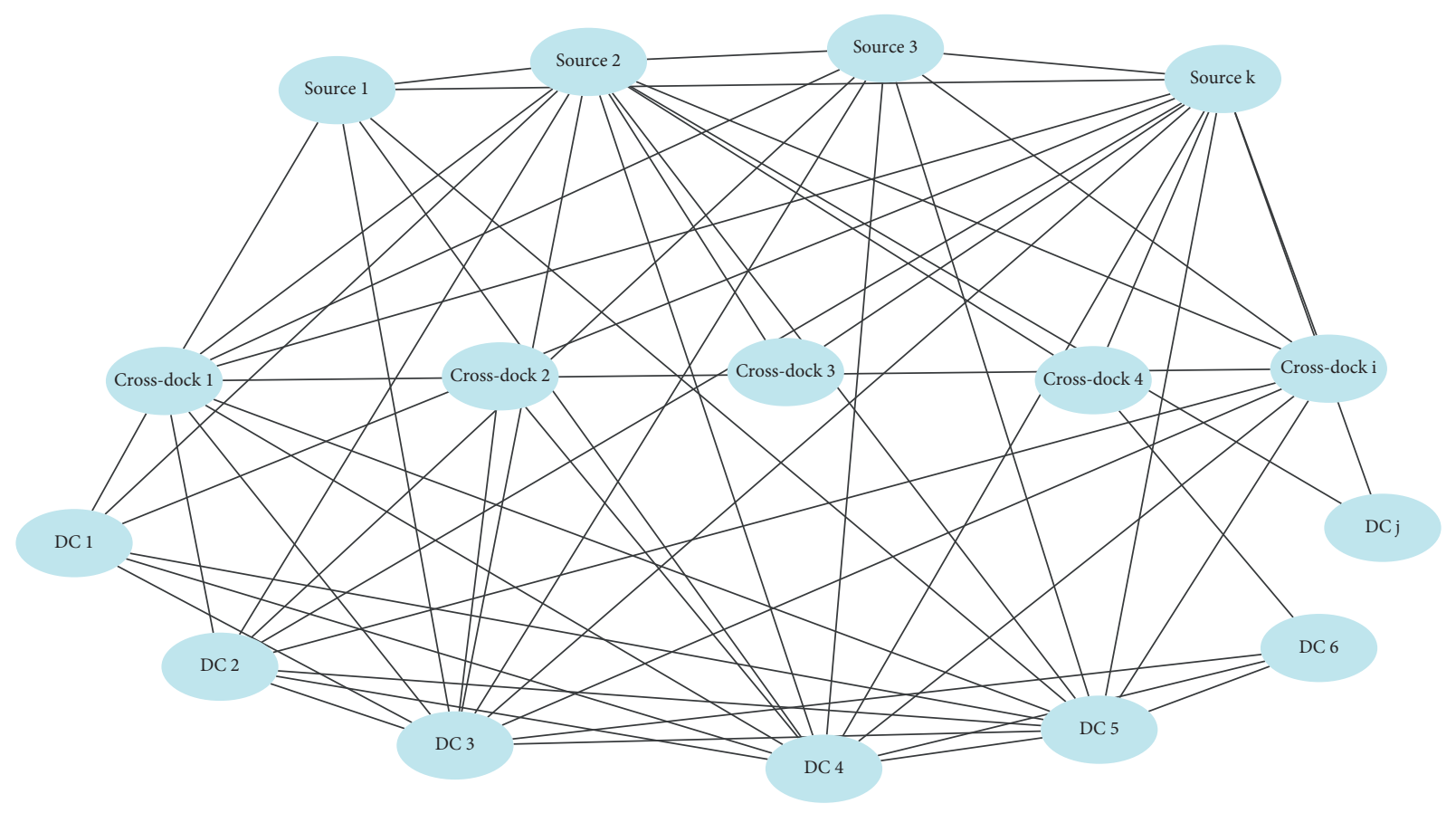

Figure 4: Typical distribution network in Mexico.

responsible for collecting vaccines in cross-docking and making the final distribution so that the biologic reaches vaccine recipients.

\subsection{Index Sets. $k \in K$ : sets of sources}

$i \in I$ : sets of cross-docking

$j \in J$ : sets of distribution center $j$

\subsection{Parameters. $Q_{k}$ : capacity of source $k$}

$K$ : capacity of cross-docking warehouse $i$

$F_{i}$ : fixed cost of the opening cross-docking warehouse in location $i$

$G_{k i}$ : transportation cost per batch of the product from the source $k$ to the cross-docking warehouse $i$

$T_{k}$ : transportation cost per batch of the product from the source $k$ to the distribution center $j$

$C_{i j}$ : cost of shipping the product from the cross-dock $i$ to the distribution center $j$

$d_{j}$ : demand of the distribution center $j$

3.5. Decision Variables. We have the following continuous variables:

$Z_{k i}$ : the amount of vaccine sent from source $k$ to the cross-dock $i$

$B_{k i}$ : the amount of vaccine sent from source $k$ to the distribution center $j$

$X_{i j}$ : the amount of vaccine sent from cross-dock $i$ to the distribution center $j$
The binary variable is as follows:

$Y_{i}= \begin{cases}1, & \text { if location } i \text { is used as a cross }- \text { docking warehouse, } \\ 0, & \text { otherwise. }\end{cases}$

Our formulation is as follows:

$$
\begin{aligned}
\operatorname{Min} \mathrm{TC}= & \sum_{k \varepsilon K} \sum_{i \varepsilon I} G_{k i} Z_{k i}+\sum_{k \varepsilon K} \sum_{j \varepsilon J} T_{k j} B_{k j} \\
& +\sum_{i \varepsilon I} F_{i} Y_{i}+\sum_{i \varepsilon I} \sum_{j \varepsilon J} C_{i j} X_{i j},
\end{aligned}
$$

subject to

$$
\begin{aligned}
& \sum_{i \varepsilon I} Z_{k i} \leq Q_{k}, \quad \forall k \varepsilon K, \\
& \sum_{j \varepsilon J} X_{i j}=\sum_{k \varepsilon K} Z_{k i}, \quad \forall i \varepsilon I, \\
& \sum_{i \varepsilon I} X_{i j} \leq d_{j}, \quad \forall j \varepsilon J,
\end{aligned}
$$

$\sum_{j \varepsilon J} X_{i j} \leq K_{i} Y_{i}, \quad \forall i \varepsilon I$,

$\sum_{k \varepsilon K} B_{k j} \leq d_{j}, \quad \forall j \varepsilon J$,

$\sum_{k \varepsilon K} Z_{k i} \leq K_{i} Y_{i}, \quad \forall i \varepsilon I$,

$\sum_{k \varepsilon K} B_{k j}+\sum_{i \varepsilon I} X_{i j}=d_{j}, \quad \forall j \varepsilon J$, 


$$
\begin{gathered}
Z_{k i} \geq 0, \quad \forall k \varepsilon K, \forall i \varepsilon I, \\
B_{k j} \geq 0, \quad \forall k \varepsilon K, \forall j \varepsilon J, \\
X_{i j} \geq 0, \quad \forall i \varepsilon I, \forall j \varepsilon J \\
Y_{i} \varepsilon\{0,1\}, \quad \forall i \varepsilon I .
\end{gathered}
$$

The objective function (2) considers, in the first term, the cost of shipping the vaccine from the sources $k$ to cross-dock warehouse $i$. The second term is the cost of shipping the vaccine from the sources $k$ to the distribution center $j$. The third term contains the fixed cost to open and operate the cross-dock warehouse $i$. The last term incorporates the cost to supply the demand of the distribution center $j$. Constraints (3) imply that all quantities shipped of sources $k$ do not violate the capacity of sources. Balanced constraints (4) ensure that the number of vaccines that arrive at a distribution center $j$ is the same as that sent to the sources. Constraints (5) guarantee that the amount of vaccines that can be sent from a cross-dock warehouse $i$ to the distribution center $j$ is less than or equal to demand. Constraints (6) bound the number of vaccines that can be sent to a distribution center $j$ from a cross-dock warehouse $i$ that has been open. Constraints (7) guarantee that the amount of vaccines that can be sent from a source $k$ to the distribution center $j$ is less than or equal to demand. Constraints (8) bound the number of vaccines that can be sent to a crossdock warehouse $i$ that has been open from the source $k$. Finally, constraints (9) ensure that the demand of each distribution center $j$ will be satisfied by a cross-dock warehouse $i$ plus quantity shipped of a source $k$.

The above formulation aims to obtain an optimal solution to the distribution network. The demand is satisfied by shipping via source to the cross-dock warehouse and the distribution center. The possible locations for the cross-dock warehouses are given, but the facilities to be used will be selected as a result of the minimum total distribution cost through a methodology that eliminates subjectivity and political preferences and ensures equitable distribution.

\section{Case Study and Limitations}

In this section, we describe the case study. In particular, we consider the distribution network for the vaccines COVID19 in Mexico. The network is made up of three echelons: seven factories, five cross-dock, and thirty-two distribution centers. Figure 4 represents the distribution network for the vaccines in Mexico. The model was solved using the Gurobi solver 9.0.2 with Python 3.8 as modeling language in a PC with Intel i5-4590S, CPU $3.00 \mathrm{GHz}, 8 \mathrm{~Gb}$ RAM, and Windows 10 as the operating system.

The coronavirus vaccination program began on December 24, 2020. The current distribution network used in the National Vaccination Strategy considers the authorized sources for the packaging of COVID-19 vaccines in Mexico, which is Liomont Laboratories located in Ocoyoacac, State of Mexico, and Drugmex located in El
Marques, Queretaro, working on packaging the doses of the AstraZeneca and CanSino Biologics vaccines, respectively. In addition, five auxiliary sources are considered when vaccine shipments arrive directly from the airports of Mexico City, Queretaro, Guadalajara, Monterrey, and Tijuana. They are considered five cross-dock in The Ministry of Defense (SEDENA for its acronym in Spanish) facilities, Birmex Laboratories, and Secretary of Health in the INCAN's warehouse, and it is assumed that you already have the necessary infrastructure and equipment to store vaccines, so they are not considered installation costs. The model considers that shipments of vaccines arriving directly from abroad must enter a crossdock to sample the batch and authorize the shipping to distribution centers operated locally by the states. Therefore, 32 distribution centers are considered.

It is envisaged that a cross-dock may receive more than one type of vaccine, but it is not restrictive that all vaccines should arrive at that facility as the state distribution does not require a mixture of vaccines but a specific amount to meet the amount of dose demand. The model provides sources to operate simultaneously as cross-dockings; they also have the infrastructure to receive vaccines from shipments from abroad. In this case, it is assumed that there is no transportation cost for shipping products from that source to your cross-dock as they are in the same geographic location. In addition, it is considered that auxiliary sources may distribute directly to states. However, the operation does not work that way; therefore, the cost of shipments from source to distribution centers is penalized for avoiding these shipments.

Each source packages a vaccine, and shipments of vaccines from abroad are only one type of biological. They are considered arrival operations only at the main international airports of the country that are protagonists of the distribution of vaccines. Shipments are considered in batches, and the specialized transport cost of the distribution network is proportional to the distance between sources, cross-dock, and distribution centers. The demand required per state was obtained from the National Institute of Statistic and Geography databases and considered the population over 18 that they should receive at least one dose of any vaccine. The capacity of the sources was estimated according to the historical capacity of the different suppliers and the capacity in the first months of operation of the authorized laboratories. This work has been created just to design a distribution network where the population older than or equal to 18 years would receive at least one dose of any of the vaccines authorized in Mexico. Therefore, vaccination was not considered in children from 12 to 17 years who have any comorbidity. Demand for vaccines follows a stable behavior, so any change in confirmed cases of COVID-19 (increase or decrease) was not considered. The distribution of vaccines within each Mexico's state was not either considered. Several factors may affect in each Mexico's states, such as the geography and distribution must be done respecting their specific belief and cultural characteristics. The information reported was obtained from national and international institutional sources; however, the data published by the 
TABLE 5: Supply ratio between cross-dock and States.

\begin{tabular}{lc}
\hline Cross-dock & States \\
\hline $\begin{array}{l}\text { Ciudad de } \\
\text { Mexico }\end{array}$ & Campeche, Chiapas, Ciudad de Mexico, Guerrero, Estado de Mexico, Morelos, Oaxaca, Puebla, Quintana Roo, Tabasco, \\
$\begin{array}{l}\text { Queretaro } \\
\text { Guadalajara }\end{array}$ & Tlaxcala, Veracruz, Yucatán \\
Monterrey & Hidalgo, Queretaro, San Luis Potosi, Tamaulipas \\
Tijuana & Aguascalientes, Colima, Durango, Guanajuato, Jalisco, Michoacan, Nayarit, Sinaloa, Zacatecas \\
Coahuila, Nuevo Leon, Chihuahua
\end{tabular}

TABLe 6: Required demand by vaccine type.

\begin{tabular}{lc}
\hline Vaccine & Demand \\
\hline Pfizer & $23,358,230$ \\
Sinovac & $13,677,792$ \\
AstraZeneca & $33,748,011$ \\
CanSino & $6,208,833$ \\
Sputnik V & $6,459,189$ \\
\hline
\end{tabular}

different levels of the Mexican government was confusing, contradictory, and possibly out of date, so there may be variations in the results of the research.

\section{Results Analysis}

The mathematical models used in the supply chain for vaccines and the performance measure used can be costs, as is traditionally done; however, there are other measures of interest such as response capacity, availability of vaccines, use of resources, or the number of lives that can be saved either in a number of people or years of life [24].

In this work, the total cost of transporting the vaccines to the distribution centers that will be in charge of distributing the vaccines to the state health centers is used as a performance measure; however, due to the information available from official authorities, this analysis will be done to compare the current distribution of vaccines against the results of the model; in this way, our analysis is based on showing which is the best way to use the resources for distribution of vaccines against COVID-19. The main interest of this work is to show the assignments to the state distribution centers and to show that there are better schemes for the use of resources.

The Mexican Government has designed a set of airline and land routes to distribute vaccines to the 32 states; see Table 3.

The case study results show a distribution proposal that can be taken into account for the redesign of the airline routes proposed by the Mexican Government. It is important to emphasize that our proposal does not consider the definition of distribution routes; it only indicates the sites where the cross-docks should be placed and shows which states could be supplied with vaccines to optimize the distribution network's costs.

The cross-docks that must be opened and operated to receive vaccines from authorized laboratories and the international supply are Mexico City, Queretaro, Guadalajara, Monterrey, and Tijuana, with an estimated annual operating cost of \$103,080,597 MXP. In addition, the candidate sites

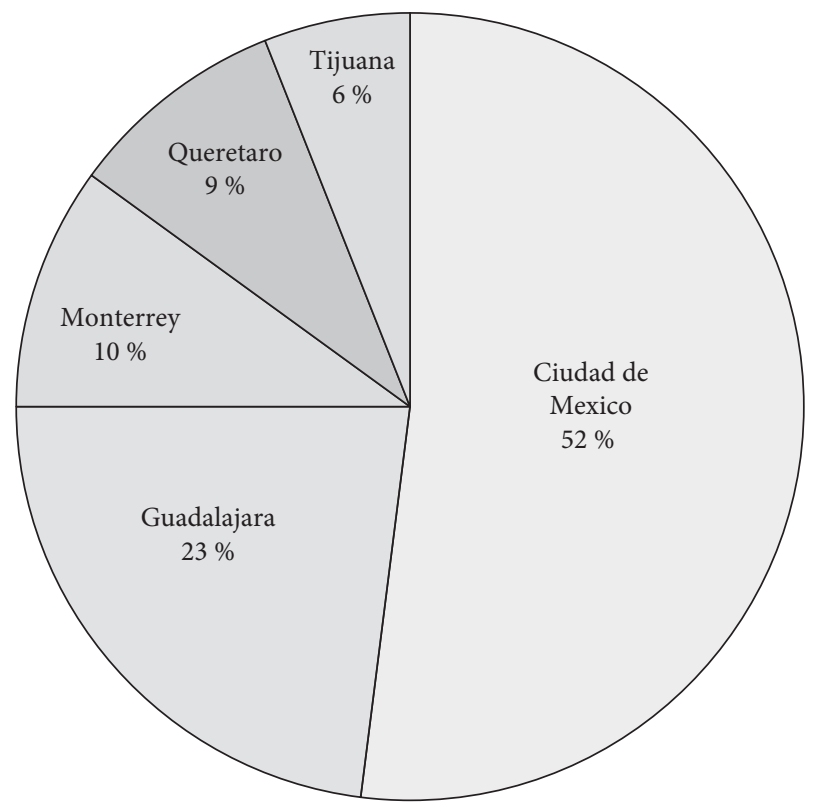

FIGURE 5: Quantity of vaccines operated per cross-dock.

were proposed considering their capacity and infrastructure for international arrivals and geographic position to supply the rest of the Republic States. Table 5 shows the distribution of Republic States that would be provided from the open cross-docking to minimize the fixed and operational costs of the distribution network and guarantee the supply of vaccines in the shortest possible time.

The model presented guarantees the sources will supply all open cross-docks to have the entire vaccine portfolio to supply the total demand of the states. However, it is important to highlight that the model does not consider the shortages in deliveries or vaccines. Table 6 shows the vaccine requirements to attend 83.5 million people in 2021 with at least one dose of the vaccines available in Mexico.

According to the information presented in Table 6, the percentage amount of vaccine management within each cross-dock is shown in Figure 5, where it can be seen that $52 \%$ of the vaccines are administrated by the Mexico City cross-dock, which is the main airport of the country.

\section{Conclusions and Future Works}

In this paper, we present a mathematical model to attend to the COVID-19 vaccine distribution problem. The case study instance involves 419 continuous variables, five binary 
variables, and 118 constraints. The model allows it to be solved optimally with Python and Gurobi, which guarantees great flexibility and efficient computation times. The proposed model assumes deterministic parameters, and the solution is very sensitive to the quality of data. In particular, the information obtained is limited since there are few public databases and the actual information is under the custody of the Government of Mexico.

The methodology used shows excellent results to design a distribution network throughout the whole country. For example, comparing the results obtained with the distribution routes described in the National Vaccination Strategy (Table 5), we can see that the cross-docks at Monterrey and Tijuana produce the same results, which gives evidence of the quality of the proposed solution, and in most of the routes, we have similarities in the vaccines supply. We highlight that the model and the input data are susceptible to the quality of information available and an equitable distribution scheme without political preferences.

There are several directions for future work, such as the following:

(i) Consider different types of transportation and distribution in each of the states so that the vaccines reach their recipients

(ii) Consider criteria that guarantee an equitable distribution among states and assign priorities based on the contagious rate

(iii) Include stochastic demand to have a more realistic problem

(iv) Consider the schedule of arrivals to build a dynamic problem that allocates according to the availability of vaccines at a specific time

\section{Data Availability}

The data used to support the findings of this study are available from the corresponding author upon request.

\section{Conflicts of Interest}

The authors declare that there are no conflicts of interest regarding the publication of this study.

\section{Acknowledgments}

The authors Isidro Soria, Hugo Pérez, and Guillermo Perea thank the Universidad Iberoamericana Ciudad de México, Departamento de Ingeniería Química, Industrial y de Alimentos, Prolongación Paseo de la Reforma 880, Colonia Lomas de Santa Fe, Álvaro Obregón, Ciudad de México 01219, México, for the support they have received. The author Rafael Torres thanks the Universidad Anáhuac México, Facultad de Ingeniería, for the support he has received.

\section{References}

[1] World Health Organization, Coronavirus Disease (COVID19), WHO, Geneva, Switzerland, 2021, https://www.who.int/ emergencies/diseases/novel-coronavirus-2019/question-andanswers-hub/q-a-detail/coronavirus-disease-COVID- 19.

[2] World Health Organization, Coronavirus (COVID-19) Dashboard, WHO, Geneva, Switzerland, 2021, https://who. int/.

[3] World Health Organization, Coronavirus (COVID-19) Dashboard, WHO, Geneva, Switzerland, 2021, https:// covid19.who.int/.

[4] Mexico's Government, Secretary of Education, Mexico's Government, National Palace, Mexico, 2020, https://www. dof.gob.mx/nota_detalle.php? codigo $=5589479 \&$ fecha $=16 / 03 /$ 2020.

[5] Mexico's Government, Conference Presidency, Mexico's Government, National Palace, Mexico, 2020, https://www. gob.mx/presidencia/es/articulos/version-estenografica-de-laconferencia-de-prensa-matutina-viernes-28-de-febrero-de2020? idiom=es.

[6] Milenio News, "Coronavirus Chronology," 2020, https:// www.milenio.com/politica/coronavirus-mexico-linea-maparesumen-covid19.

[7] Mexico's Government, Secretary of Health, Mexico's Government, National Palace, Mexico, 2021, https://vacunacovid. gob.mx/wordpress/.

[8] World Health Organization, COVID-19 Vaccines, WHO, Geneva, Switzerland, 2021, https://www.who.int/ emergencies/diseases/novel-coronavirus-2019/COVID-19vaccines.

[9] World Health Organization, The COVID-19 Candidate Vaccine Landscape and Tracker, WHO, Geneva, Switzerland, 2021, https://www.who.int/publications/m/item/draftlandscape-of-COVID-19-candidate-vaccines.

[10] Launch and Scale Speedometer, "Vaccine procurement," 2021, https://launchandscalefaster.org/COVID-19/ vaccineprocurement.

[11] World Health Organization, COVAX Working for Global Equitable Access to COVID-19 Vaccines, WHO, Geneva, Switzerland, 2021, https://www.who.int/initiatives/actaccelerator/covax.

[12] Coalition for Epidemic Preparedness Innovations (CEPI), COVAX: CEPI's Response to COVID-19, CEPI, Oslo, Norway, 2021, https://cepi.net/covax/.

[13] Global Alliance for Vaccines and Immunizations (GAVI), COVAX Vaccine Roll-Out, GAVI, Geneva, Switzerland, 2021, https://www.gavi.org/covax-facility.

[14] United Nations International Children's Emergency Fund (UNICEF), COVAX: Ensuring Global Equitable Access to COVID-19 Vaccines, UNICEF, New York, NY, USA, 2021, https://www.unicef.org/supply/covax-ensuring-globalequitable-access-COVID-19-vaccines.

[15] Americas Society (AS) - Council of Americas (COA), Timeline: Tracking Latin America's Road to Vaccination, COA, New York, NY, USA, 2021, https://www.as-coa.org/articles/ timeline-tracking-latin-americas-road-vaccination.

[16] Mexico's Government, Presidential Conference, Mexico's Government, National Palace, Mexico, 2020, https:// lopezobrador.org.mx/2020/10/13/version-estenografica-de-la -conferencia-de-prensa-matutina-del-presidente-andres-ma nuel-lopez-obrador-395/. 
[17] https://www.gob.mx/salud/prensa/mexico-recibe-primerembarque-de-vacunas-pfizer-biontech-contra-el-virus-sarscov-2-260177?idiom=es Mexico's Government, Press Release, December 23rd, 2020.

[18] Proceso Magazine, "Vaccines. Mexico receives 2.2 million of vaccines through COVAX initiative," 2021, https://www. proceso.com.mx/nacional/2021/5/27/mexico-recibe-elcargamento-mas-grande-de-vacunas-millones-229-mil-deastrazeneca-264763.html.

[19] Mexico's Government, Presidential Conference, Mexico's Government, National Palace, Mexico, 2021, https:// presidente.gob.mx/12-01-21-version-estenografica-de-laconferencia-de-prensa-matutina-del-presidente-andresmanuel-lopez-obrador/.

[20] https://birmex.gob.mx/news/recibe-mexico-mas-de-700-mildosis-de-vacunas-envasadas-de-astrazeneca-contra-COVID19/ Birmex Laboratories, Press release, May 23rd, 2021.

[21] S. Lemmens, C. Decouttere, N. Vandaele, and M. Bernuzzi, "Integrated supply chain network design models for vaccines: a literature review," Faculty of Economics, Business, vol. 1414, pp. 1-75, 2014.

[22] J. Lim, B. A. Norman, and J. Rajgopal, "Redesign of vaccine distribution networks," International Transactions in Operational Research, vol. 29, pp. 1-26, 2019.

[23] S.-I. Chen, B. A. Norman, J. Rajgopal, T. M. Assi, B. Y. Lee, and S. T. Brown, "A planning model for the WHO-EPI vaccine distribution network in developing countries," IIE Transactions, vol. 46, no. 8, pp. 853-865, 2014.

[24] S. J. Sadjadi, Z. Ziaei, and M. S. Pishvaee, "The design of the vaccine supply network under uncertain condition: a robust mathematical programming approach," Journal of Modelling in Management, vol. 14, no. 4, pp. 841-871, 2019.

[25] H. K. Smalley, P. Keskinocak, J. Swann, and A. Hinman, "Optimized oral cholera vaccine distribution strategies to minimize disease incidence: a mixed integer programming model and analysis of a Bangladesh scenario," Vaccine, vol. 33, no. 46, pp. 6218-6223, 2015.

[26] C. T. Ng, T. C. E. Cheng, D. Tsadikovich, E. Levner, A. Elalouf, and S. Hovav, "A multi-criterion approach to optimal vaccination planning: method and solution," Computers \& Industrial Engineering, vol. 126, pp. 637-649, 2018.

[27] Y. Yang and J. Rajgopal, An Iterative Cyclic Algorithm for Designing Vaccine Distribution Networks in Low and MiddleIncome Countries, Springer, Berlin, Germany, pp. 512-521, 2020.

[28] S. T. Brown, B. Schreiber, B. E. Cakouros et al., "The benefits of redesigning Benin's vaccine supply chain,” Vaccine, vol. 32, pp. 4097-4103, 2014.

[29] M. U. Farooq, A. Hussain, T. Masood, and M. S. Habib, "Supply chain operations management in pandemics: a stateof-the-art review inspired by COVID-19," Sustainable Times, vol. 13, pp. 1-33, 2021.

[30] M. Vledder, J. Friedman, M. Sjöblom, T. Brown, and P. Yadav, "Improving supply chain for essential drugs in low-income countries: results from a large-scale randomized experiment in Zambia," Health Systems \& Reform, vol. 5, no. 2, pp. 158-177, 2019.

[31] K. De Boeck, C. Decouttere, and N. Vandaele, "Vaccine distribution chains in low- and middle-income countries: a literature review," Omega (United Kingdom). Elsevier Ltd, vol. 97, 2020.

[32] I. Soria Arguello, Rediseño de la Cadena de Abastecimiento de un Grupo Embotellador de Bebidas, ITESM Campus Toluca, Toluca de Lerdo, Méx., Mexico, 2008.
[33] J. A. Marmolejo, I. Soria, and H. A. Perez, "A decomposition strategy for optimal design of a soda company distribution system," Mathematical Problems in Engineering, vol. 2015, Article ID 891204, 7 pages, 2015.

[34] J. A. Lozano-Diez, J. A. Marmolejo-Saucedo, and R. Rodriguez-Aguilar, "Designing a resilient supply chain: an approach to reduce drug shortages in epidemic outbreaks," EAI Endorsed Trans Pervasive Heal Technol, vol. 6, pp. 1-12, 2020. 